\title{
Enhancement of Low Voltage Ride Through Capability of Doubly Fed Induction Generator Based Wind Turbine Using Fuzzy Logic Controller
}

\author{
$G$ Manohar, ${ }^{*}, S$ Venkateshwarlu ${ }^{2}$, and $A$ Jaya Laxmi ${ }^{1}$ \\ ${ }^{1}$ JNTU College of Engineering, Kukatpalli, Hyderabad, India \\ ${ }^{2}$ CVR College of Engineering, Hyderabad, India
}

\begin{abstract}
Combined impact of environmental issues and policies of utilities has led to generation of clean and sustainable energy. Solar and wind energies are prominent and can provide bulk amount of electrical energy. Vast number of resources and more electrical energy density are attractive features of wind energy. Generation of bulk amount of wind energy especially offshore wind energy is attracting utilities to incline towards wind energy. Variable speed wind energy conversion systems employing Doubly fed induction generators offers several advantages such as maximum power generation and independent control of active and reactive powers. Doubly fed induction generator-based wind energy system became the first choice of power system operators due to its low-cost power electronic convertors. Stringent grid codes adopted by various countries made Low voltage ride through a serious problem for electric utilities as well as DFIG manufacturers. Many researchers tried to address the problem of low voltage ride through. In initial stages, crowbar circuits were used. Later Low voltage ride through was addressed using additional hardware such as STATCOM. Artificial intelligent controllers were used to minimize the effect of ride through. A comprehensive review, of different issues allied with low voltage ride through of doubly fed induction generator-based wind energy conversion system is presented in this article.
\end{abstract}

\section{Introduction}

The continuous growth of electrical energy demand and increased carbon dioxide footprint has resulted in the inclination of the generation of renewable energy. Both the policymakers and utilities are gradually increasing the production of pollution-free energy. Even though there are many types of renewable sources are available, solar and wind energy are prominent due to their bulk production and compatibility with electrical grid code requirements. Less requirement of the land and bulk power generation per unit made wind energy attractive and promising[1]. China continues to be the world leader in wind generation with an installed capacity of $221 \mathrm{GW}$, while India has an installed capacity of $35.6 \mathrm{GW}$ standing in the fourth position in the world.

Fixed speed wind generators were used in the initial stages of wind power generation and their applications were mostly limited to isolated loads. Squirrel cage induction generators were used to generate electrical energy. Advantages of such systems are reliability, low cost and simple operation. Requirement of capacitor banks, fluctuations in voltage and power were severe limitations of fixed-speed wind energy systems. In later stages of development, limited variable speed WECS employing wound rotor induction generator came into the picture. In this type of WECS, electronically controlled rheostats were used to control the slip of the induction generator. The narrow range of speed control, high rotor resistance losses, and low efficiency made this system to become absolute. The concepts were first commercialized by the Dutch wind turbine manufacturing company Lagerwey and Enercon of Germany. Variable speed wind energy conversion systems generate variable frequency voltage and thus requires power electronic converters to generate constant frequency voltage. Apart from maintaining frequency constant, power electronic converters also regulate the voltage generated by the wind generator [2].

Variable speed wind energy conversion systems mainly employ either squirrel cage induction generators with full rated power electronic converters or wound rotor induction generator employing partial rated power electronic converters. In Variable speed wind energy conversion systems employing squirrel cage generator, the stator of the squirrel cage induction generator is connected to the electrical grid through a back-to-back connected power electronic converter. The rating of the power electronic converter is same as the squirrel cage induction generator. The function of these back-to-back power electronic converter is regulating the frequency. Since full rated power electronic converters are to be used, the cost of the WECS is much higher [3]. Employing of synchronous generators in variable speed

\footnotetext{
* Corresponding author: manohar.gangikunta@gmail.com
} 
WECS are less and still used in few places where grid code requirements are stringent in terms of voltage and reactive power assistance at the time of fault conditions. Overall manufacturing cost increases due to the usage of full rated power electronic converters are connected between stator of the synchronous generators and grid. Bulk power output, low initial cost and adoptability to grid requirements made Power system operators and utilities to incline towards wind power generation using doubly fed induction generator.

\section{Doubly Fed Induction Generator}

Construction wise stator of doubly fed induction generator is like that of wound rotor induction motor and is directly linked to electrical grid whereas rotor is linked to the electrical grid through partial rated power electronic converters. A variable wind turbine is generally coupled to the DFIG. The wind turbine is designed to deliver maximum mechanical energy from the given wind speed. The variable turbine changes the angle of the blades to maximize its output power. Hence the input mechanical energy to DFIG continuously varies and thus its output voltage and frequency varies. Since DFIG is connected to electrical grid, the frequency of the output voltage must be controlled. The back-toback connected power electronic controllers acts to maintain frequency constant. The major advantages of DFIG are independent control of active and reactive power and easy implementation of maximum power point tracking to extract maximum power. The convertor connected to rotor of the circuit is generally named as rotor side converter and the converter connected to grid is named as grid side converter [4]. Doubly fed induction generator connected to grid is shown in "Fig. 1"

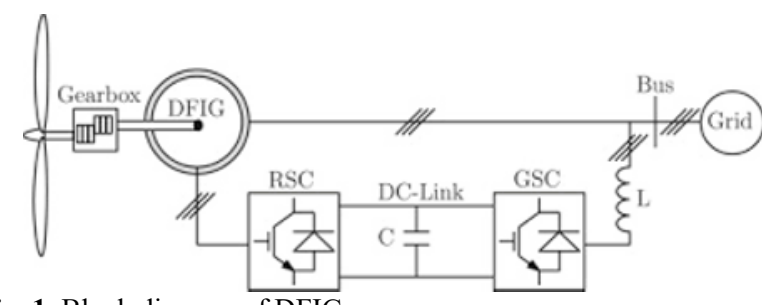

Fig. 1. Block diagram of DFIG

\section{Mathematical modelling of doubly fed induction generator}

Stator of the Doubly fed Induction generator is a threephase slip ring induction motor in which stator is directly linked to electrical grid whereas rotor is linked to the electrical grid through sliprings and partial rated power electronic converters. Generally, a transformer is connected between grid side converter and electrical grid. Equivalent circuit of DFIG is shown in "Fig.2.".

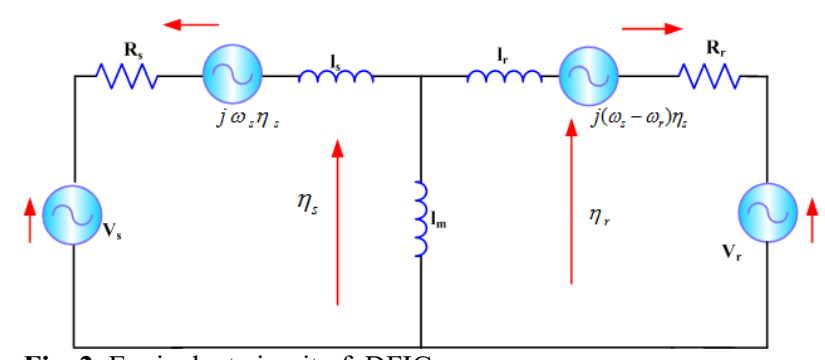

Fig. 2. Equivalent circuit of DFIG

Flux equations and stator and rotor voltages of DFIG are described as follows.

$$
\begin{aligned}
& V_{D S}=R_{s} I_{D S}+\frac{d \eta_{D S}}{d t}-\omega_{s} \eta_{Q S} \\
& V_{Q S}=R_{s} I_{Q S}+\frac{d \eta_{Q S}}{d t}-\omega_{s} \eta_{D S} \\
& V_{D R}=R_{r} I_{D R}+\frac{d \eta_{D R}}{d t}-\left(\omega_{s}-\omega_{r}\right) \eta_{Q R} \\
& V_{Q R}=R_{r} I_{Q R}+\frac{d \eta_{Q R}}{d t}+\left(\omega_{s}-\omega_{r}\right) \eta_{D R} \\
& {\left[\begin{array}{l}
\eta_{D S} \\
\eta_{D R}
\end{array}\right]=\left[\begin{array}{ll}
l_{s} & l_{m} \\
l_{m} & l_{r}
\end{array}\right]\left[\begin{array}{l}
I_{D S} \\
I_{D R}
\end{array}\right]} \\
& {\left[\begin{array}{l}
\eta_{Q S} \\
\eta_{Q R}
\end{array}\right]=\left[\begin{array}{ll}
l_{s} & l_{m} \\
l_{m} & l_{r}
\end{array}\right]\left[\begin{array}{l}
I_{Q S} \\
I_{Q R}
\end{array}\right]}
\end{aligned}
$$

Here ,

$$
\begin{aligned}
& l_{s}=l_{s}+l_{m} \\
& l_{r}=l_{r}+l_{m} \\
& \eta_{D S}=l_{s} I_{D S}+l_{m} I_{D R} \\
& \eta_{Q S}=l_{s} I_{Q S}+l_{m} I_{Q R} \\
& \eta_{D R}=l_{r} I_{D R}+l_{m} I_{D S} \\
& \eta_{Q R}=l_{r} I_{Q R}+l_{m} I_{Q S}
\end{aligned}
$$

Here, $R_{s}$ and $R_{r}$ is represented as stator and rotor resistance.

\section{Low voltage ride through and probable solutions}

During grid faults, there is a voltage dip at one or more phases. As a result of this, stator voltage changes. Stator flux cannot track the rapid changes in the stator voltage and stator flux becomes almost static. The rotor keeps revolving as a result, there will be high slip produced. Due to this, very high voltages are induced in the rotor circuit of DFIG leading to high currents in the power 
electronic converters. These high currents can damage the power electronic converters connected in the rotor circuit of DFIG. The DFIG cannot synthesize the commands to protect its power electronic converter. A huge amount of research is carried out to analyse the behaviour of DFIG under the condition of voltage dips [5-9].

Under such situations, in early years crowbar circuits were used to protect the rotor circuit of DFIG. This crowbar circuit shorts the rotor circuit and hence defends the power electronic converters from over currents. Crowbar circuits used to protect the DFIG under voltage dips are shown in "Fig.3". The major problem with this approach is when rotor gets short circuited, DFIG acts as squirrel cage motor and thus consuming reactive power from the grid. This further increases the severity of problem in grid connected systems. As a result of high-capacity wind power penetration into grid, most of the countries are introducing stringent grid codes. According to these grid codes, the wind power plants should remain connected to the grid in case of voltage dips for certain duration of time and wind power plants are expected to supply reactive power to the grid. Characteristics of the grid codes and grid codes of different countries are shown in "Fig.4" and "Fig.5.".
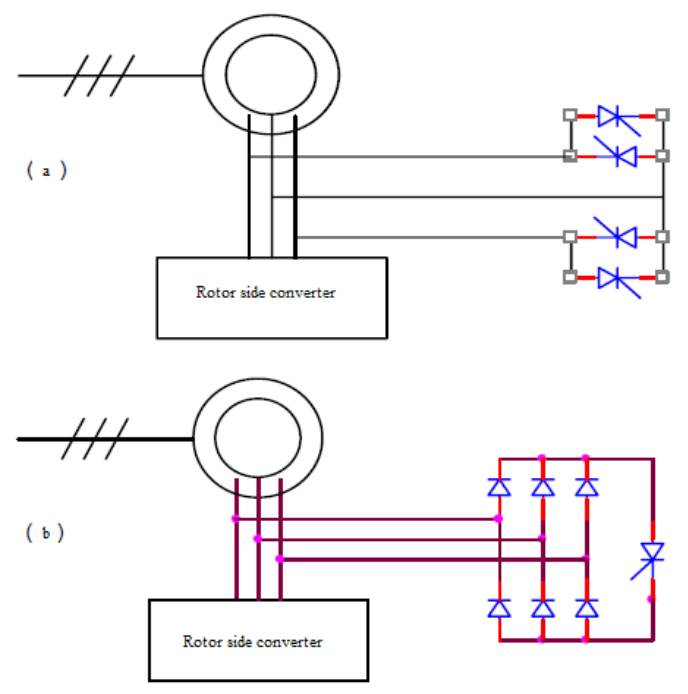

Fig.3. Conventional Crowbar circuits

(a) crowbar circuit employing thyristors

(b) Diode bridge crowbar

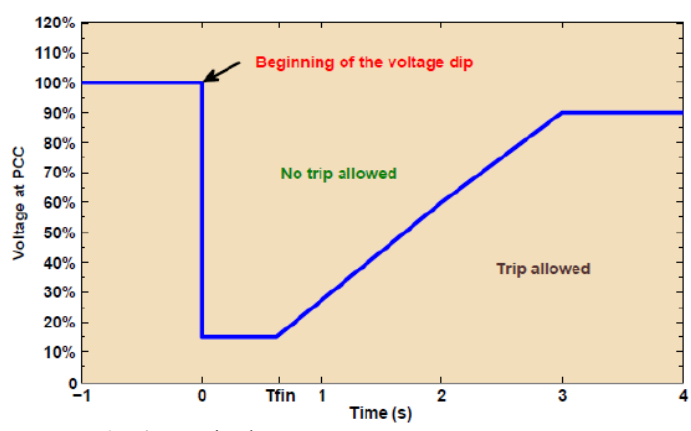

Fig.4. Typical LVRT curve

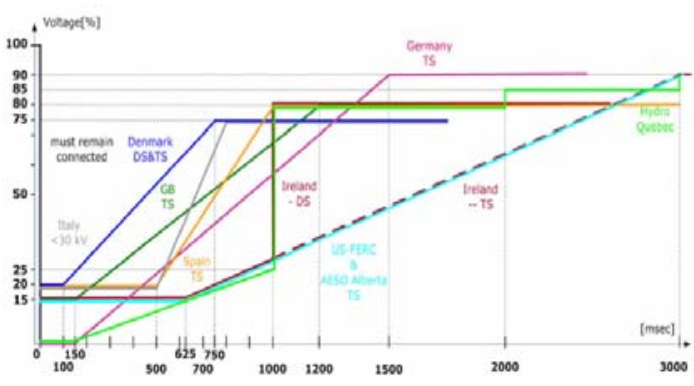

Fig.5. LVRT requirements of different countries

The major problem with this approach is when rotor gets short circuited, DFIG acts as squirrel cage motor and thus consuming reactive power from the grid. This further increases the severity of problem in grid connected systems. As a result of high-capacity wind power penetration into grid, most of the countries are introducing stringent grid codes. According to these grid codes, the wind power plants should remain connected to the grid in case of voltage dips for certain duration of time and wind power plants are expected to supply reactive power to the grid.

A DC-DC converter functioning in parallel with DC link of Doubly fed induction generator can control both Energy Storage System (ESS) and amount of active power generated. The Super Magnetic Energy Storage (SMES) unit is highly efficient and has the ability of power controllability with fast dynamic response. The circuit diagram of SMES unit in the DC link of DFIG is shown in "Fig.6". Niobium Titanium (NbTi) or Niobium Tin $\left(\mathrm{Nb}_{3} \mathrm{Sn}\right)$ are generally used super conducting materials used in SMES unit. The DC chopper is made to operate effectively to control the power transfer effectively between SMES unit and rotor of DFIG and power grid.

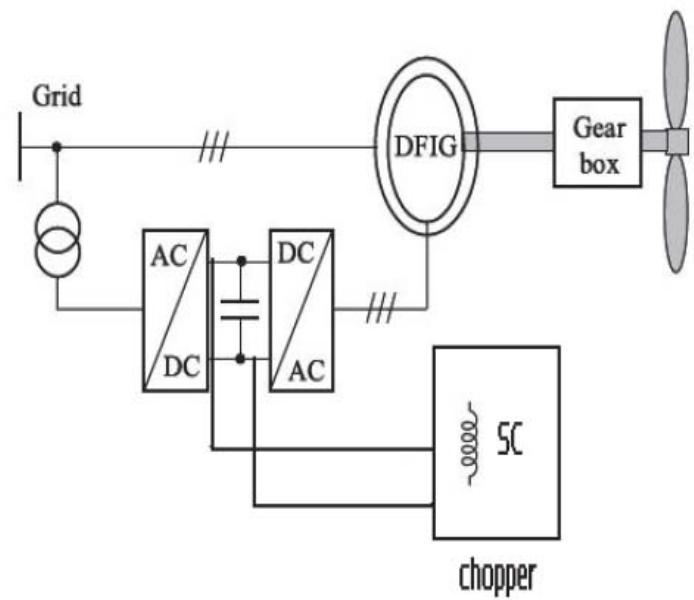

Fig.6. The circuit diagram of DFIG employing SMES unit

Energy Storage System (ESS) is an alternative methodology to boost low voltage ride through ability of DFIG. In this approach an efficient energy storage system is placed in the DC link of DFIG. Energy storage system comprises of two series connected bidirectional 
switches and ESS is connected in parallel with one of the switches as shown in "Fig.7". ESS based methods can effectively control the doubly fed induction generator during grid faults also. Necessity of additional semiconductor switches and energy storage system increases over all cost and complexity of the system [1012].

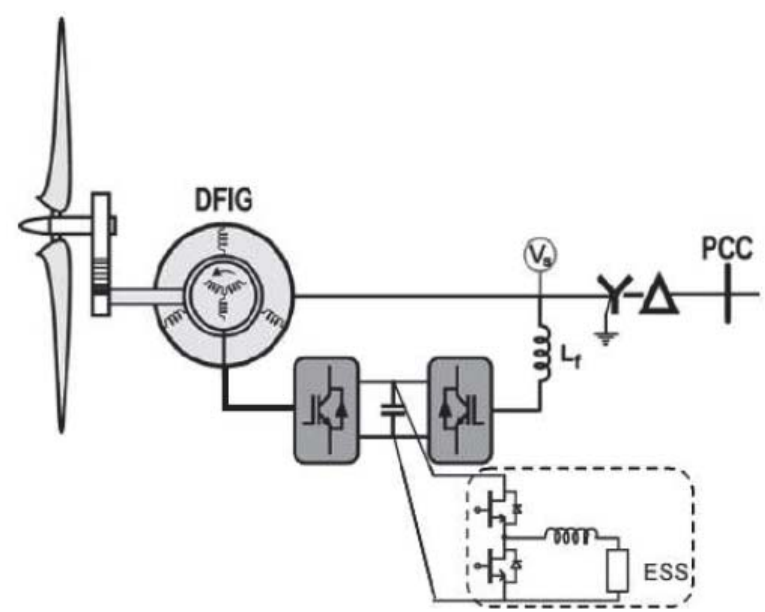

Fig.7. DFIG based wind energy conversion system equipped with ESS

Another solution to enhance LVRT capability of DFIG is presented in [13]. The presented configuration uses a parallel Grid Side Rectifier (PGSR) with the combination of Series Grid Side Converter (SGSR) as shown in "Fig.8". These two converters enable continuous power processing and provides low voltage ride through of DFIG. Series Side Grid Converter (SGSC) function is to infuse DC link power into the electrical grid.

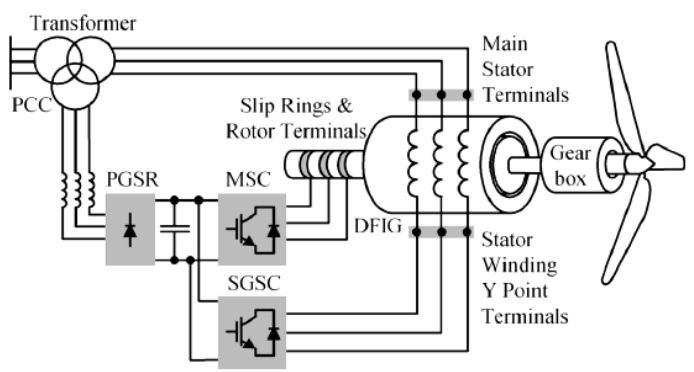

Fig.8. DFIG based wind energy conversion system with PGSR and SGSC

Improvement of LVRT of DFIG can also be achieved by using Series Dynamic Resistor (SDR) as shown in "Fig.9". In this configuration, a dynamic resistor is connected in series between rotor windings and Rotor Side Converter (RSC) of the DFIG [14]. The purpose of connecting the dynamic resistor is to limit the rotor over currents occurring during grid voltage dips. The highspeed semiconductor power electronic switch controls the operation of SDR. This power electronic switch is normally closed under steady state conditions to short the dynamic resistor and during fault conditions this switch opens and dynamic resistor is activated to limit the rotor current.

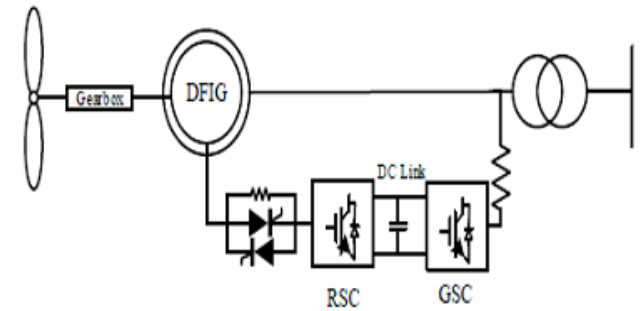

Fig.9. DFIG with Series Dynamic Resistor(SDR) for enhancing LVRT

The Static Synchronous Compensator is an alternative method to enrich LVRT capability of DFIG.STATCOM is a power electronic converter works on voltage source converter principle. STATCOM connected in DFIG circuit to enhance LVRT capability is shown in "Fig.10". During steady state conditions, to improve voltage regulation and stability the STATCOM can inject or absorb reactive power from electric grid. A STATCOM can inject maximum reactive current into electric grid to provide smooth and rapid reactive power compensation [15-16]. Another advantage of using STATCOM in DFIG based wind turbines is compensation of current independent of voltage level at the connection point during fault conditions [17-19].

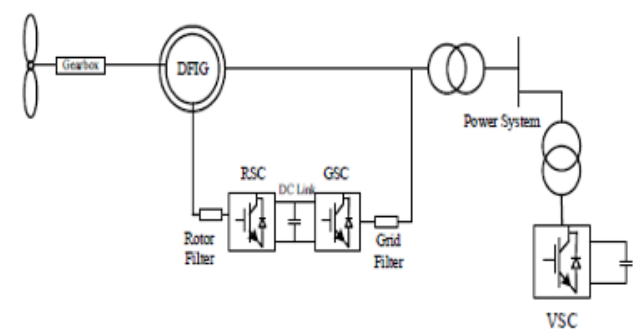

Fig.10. DFIG with Static Synchronous Compensator(STATCOM)

Series Dynamic Braking Resistor (SDBR) connected between stator and electric grid is an alternative approach to enhance LVRT capability of DFIG [20]. SDBR protection circuit employed in DFIG to enhance LVRT capability is shown in "Fig.11". SDBR protection circuit can enhance the terminal voltage during grid voltage dips.

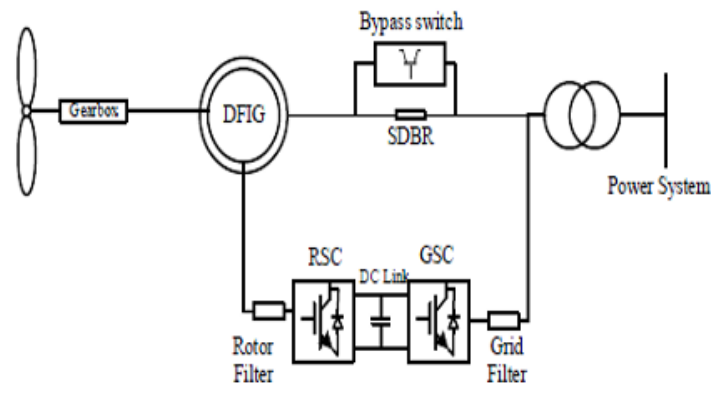

Fig .11. DFIG with Series Dynamic Braking Resistor (SDBR) for enhancing LVRT

Even though, mechanical methods like stall control and blade pitch angle control are available, their applications 
are limited to only constant speed wind turbines. Hence those methods are not suitable for DFIG. Most of the methods conversed to improve LVRT ability of DFIG are using additional equipment. This equipment not only increase the complexity and control, but also increase overall cost of the wind energy conversion system. Hence the researchers and manufacturers of DFIG started to enhance LVRT of DFIG by using additional controllers rather than using additional equipment. Sliding mode method for enrichment LVRT capability of DFIG was considered in [21-22]. A genetic algorithm based optimal design for DFIG is presented in [23]. An ant line recurrent neural network controller for enhancing LVRT of DFIG is presented in [24]. An efficient hybrid Modified elephant herding random forest algorithm to enhance LVRT of DFIG is proposed in [25].

\section{Enhancement of low voltage ride through capability using fuzzy logic controller}

Compared to the traditional PI controller, an accurately designed fuzzy logic controller can limit the rotor current during fault condition. Major advantage of fuzzy logic controller is that it acts as a protective circuit when DFIG is subjected to external fault conditions. Fuzzy logic controller offers several advantages compared to PI controller in enhancing LVRT capability of DFIG [26]. They are

- Calculation of variable gains in accordance with error are easier

- Quite simple in solving problems

- Fast convergence

- Un effected by Noise and in accurate signals

A fuzzy logic controller is designed in MATLAB Simulink with triangular membership functions. The inputs to the fuzzy controller are error, integral of error and measured reactive power at the point of contact coupling and the outputs are reference values of reactive power and active power as shown in "Fig.12". Mamdani type of Fuzzy logic controller was used in simulation.

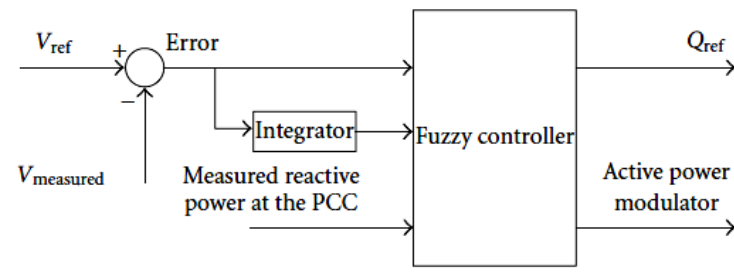

Fig.12. Fuzzy Controller for enhancement of LVRT of DFIG

Fuzzy sets of output as well as input assign the following names: NB: Negative-Big, NM: Negative-Medium, NS: Negative-Small, ZE :Zero, PS: Positive-Small, PM: Positive-Medium and PB: Positive.-Big. Seven triangular functions have been assigned to inputs and outputs. Membership functions of input and output are shown in "Fig.13", Fig.14" and "Fig.15" respectively.

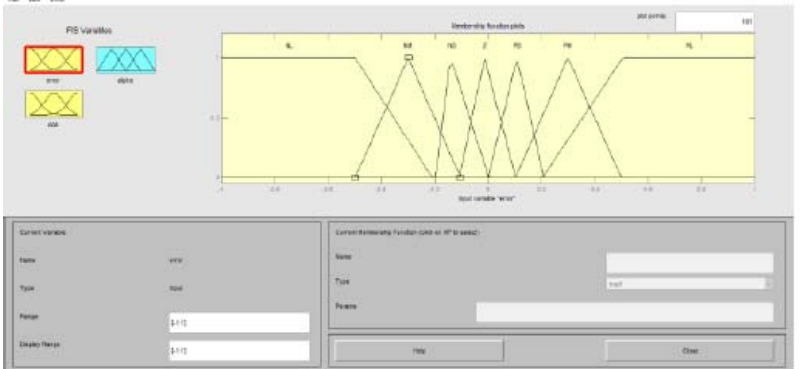

Fig.13. Triangular Membership functions for the input error

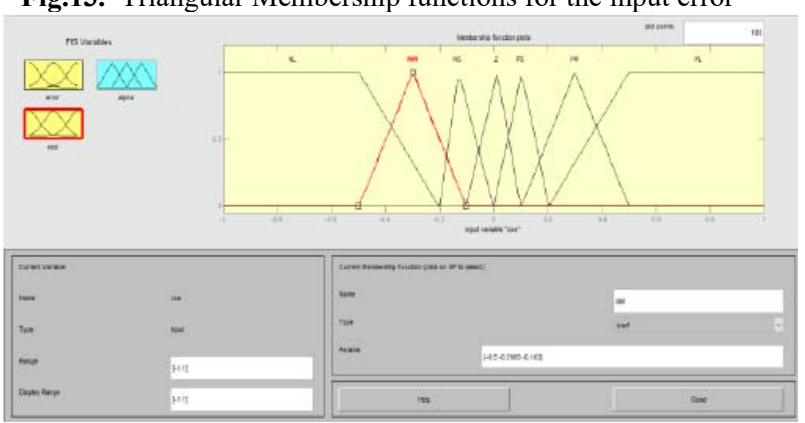

Fig.14. Triangular Membership functions for the input change

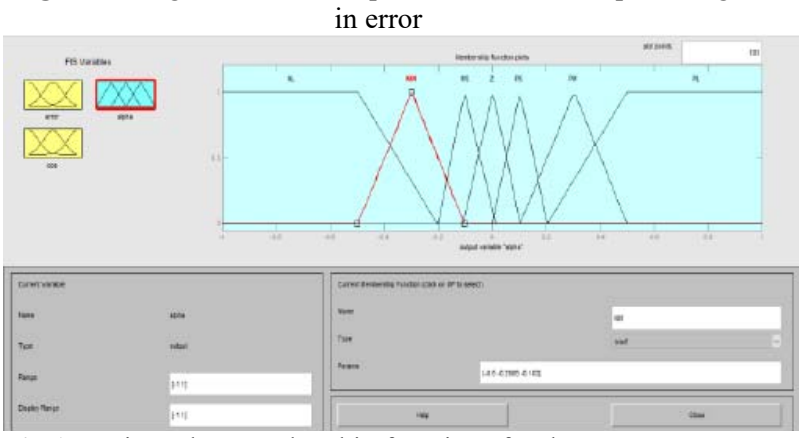

Fig.15. Triangular Membership functions for the output

Per phase rotor voltage with conventional vector control using PI controller is shown in "Fig.16". There was a fault created for $0.2 \mathrm{~S}$ from $7.9 \mathrm{~S}$ to $8.1 \mathrm{~S}$ and rotor phase voltage drops from $2200 \mathrm{~V}$ to $1000 \mathrm{~V}$ and a dip of $1200 \mathrm{~V}$ was observed. Per phase rotor voltage with fuzzy logic controller is shown in "Fig.17". There was a fault created for $0.2 \mathrm{~S}$ from $7.9 \mathrm{~S}$ to $8.1 \mathrm{~S}$ and rotor phase voltage drops from $740 \mathrm{~V}$ to $380 \mathrm{~V}$ and a dip of $360 \mathrm{~V}$ was observed.

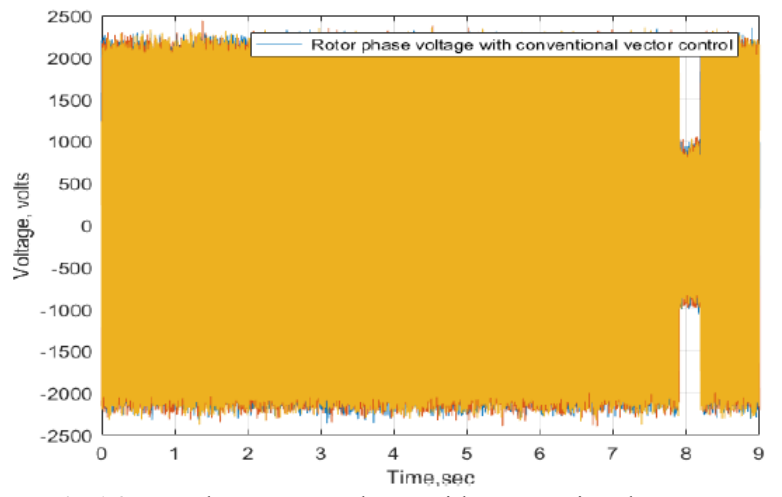

Fig.16. per phase rotor voltage with conventional vector control 


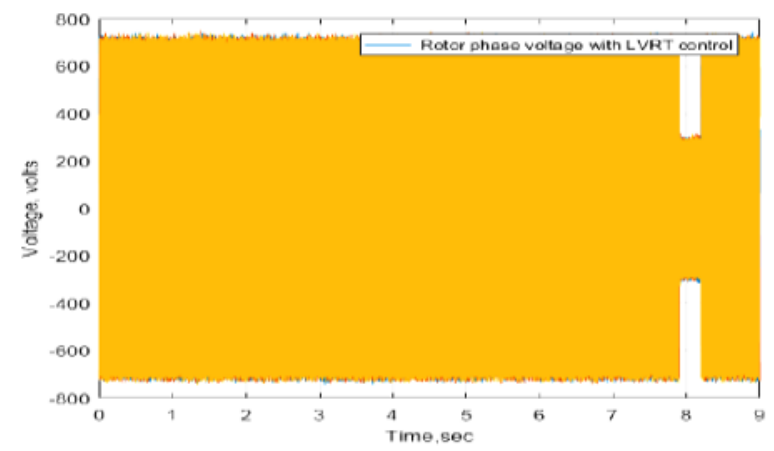

Fig .17. per phase rotor voltage with Fuzzy logic controller

\section{Conclusion}

In this paper, different types of wind energy conversion systems are discussed. The causes of low voltage ride through of a doubly fed induction generator connected to grid were presented. Probable solutions for low voltage ride through were analysed and compared. Low voltage ride through solutions involving with and without additional power electronic hardware are discussed and compared. DFIG with conventional vector control and Fuzzy logic controller are analysed and compared and found that the enhancement of LVRT is better with fuzzy logic controller.

\section{References}

[1] Chowdhury, B.H. and Chellapilla, S., 2006. Doublefed induction generator control for variable speed wind power generation. Electric power systems research, 76(9-10), pp.786-800.

[2] Jadhav, H.T. and Roy, R., 2013. A comprehensive review on the grid integration of doubly fed induction generator. International Journal of Electrical Power \& Energy Systems, 49, pp.8-18.

[3] Béchir, B., Faouzi, B. and Gasmi, M., 2012. Wind energy conversion system with full-scale power converter and squirrel cage induction generator. International Journal of Physical Sciences, 7(46), pp.6093-6104.

[4] Manohar, G. and Venkateshwarlu, S., 2016. Analysis of Grid connected Doubly Fed Induction Generator based Wind Turbine. CVR Journal of Science and Technology, 10, pp.59-64.

[5] J. Niiranen "Voltage Dip Ride Through of a doubly fed system" World Wide Energy Conference, 2004.

[6] T. Thiringer, A. Petersson, T. Petru, "Grid disturbance response of wind turbines equipped with induction generator and doubly-fed induction generator",Power engineering society annual meeting, Toronto, Canada july, 2003

[7] S. Seman, J. Niiranen, S. Kanerva, A. Arkkio, "Analysis of a 1.7 MVA Doubly Fed Wind-Power Induction Generator during Power Systems Disturbances", Nordic Workshop on Power and Industrial Electronics, Trondheim, 2004

[8] Petersson, S. Lundberg, T. Thiringer “A DFIG wind-turbine ride through system influence on energy production", Nordic Wind Power Conference, march 1-2, 2004
[9] J. Niiranen, "Voltage ride through of a doubly-fed generator equipped with an active crowbar", Nordic Wind Power Conference, March 1-2, 2004.

[10] A.H.M.A. Rahim and E.P. Nowicki, "Supercapacitor energy storage system for fault ride-through of a DFIG wind generation system," Energy Conversion and Management, vol. 59, pp. 96-102, July 2012

[11] M.J. Hossain, H.R. Pota, V.A. Ugrinovskii and R.A. Ramos, "Improved low-voltage-ride-through capability of fixed speed wind turbines using decentralised control of STATCOM with energy storage system," IET Generation, Transmission \& Distribution, vol. 6, n8, pp. 719-730, 2012.

[12] C. Abbey and G. Joos, "Supercapacitor energy storage for wind energy applications," IEEE Trans. Industry Applications, vol. 43, n³, pp. 769776, May-June 2007.

[13] P.S. Flannery and G. Venkataramanan, "A fault tolerant doubly fed induction generator wind turbine using a parallel grid side rectifier and series grid side converter," IEEE Trans. Power Electronics, vol. 23, n³, pp. 1126-1135, May 2008.

[14] Gray, C.; Buque, C.; Chowdhury, S. AC series dynamic resistor protection scheme with switching control for doubly fed induction generator based WECS. In Proceedings of the 2016 IEEE Power and Energy Society General Meeting (PESGM), Boston, MA, USA,17-21 July 2016; pp. 1-5.

[15] Acha, E. Power Electronic Control in Electrical Systems; Newnes Power Engineering Series: Oxford, UK, 2002.

[16] Kanchanaharuthai, A.; Chankong,V.; Loparo, K.A. Transient Stability and Voltage Regulation in Multimachine Power Systems Vis-à-Vis STATCOM and Battery Energy Storage. IEEE Trans. Power Syst. 2015, 30, 2404-2416.

[17] Li, N.; Wang, L.; Yang, H.; Ma, H. Stability Analysis for SSR of DFIG-Based Wind Farm Considering STATCOM Capacity Constraint. In Proceedings of the 2019 22nd International Conference on Electrical Machines and Systems (ICEMS), Harbin, China, 11-14 August 2019; pp. $1-6$.

[18] Molinas, M.; Suul, J.A.; Undeland, T. Low Voltage Ride Through of Wind Farms With Cage Generators: STATCOM Versus SVC. IEEE Trans. Power Electron. 2008, 23, 1104-111.

[19] Tang, Y.; He, H.; Ni, Z.; Wen, J.; Huang, T. Adaptive Modulation for DFIG and STATCOMWith High-Voltage Direct Current Transmission. IEEE Trans. Neural Netw. Learn. Syst. 2016, 27, 1762-1772.

[20] Alam, M.S.; Hossain, M.I.; Hossain, M.A.; Choudhory, M.S.H.; Uddin, M.A. Protection of Inverter-based Distributed Generation with Series Dynamic Braking Resistor: A Variable Duty Control Approach. In Proceedings of the 2018 10th International Conference on Electrical and Computer Engineering (ICECE), Dhaka, Bangladesh, 20-22 December 2018; pp. 253-256.

[21] Saad, N.H., Sattar, A.A. and Mansour, A.E.A.M., 2015. Low voltage ride through of doubly-fed induction generator connected to the grid using sliding mode control strategy. Renewable Energy, 80, pp.583-594.

[22] Benbouzid, M., Beltran, B., Amirat, Y., Yao, G., Han, J. and Mangel, H., 2013, November. Highorder sliding mode control for DFIG-based wind turbine fault ride-through. In IECON 2013-39th Annual Conference of the IEEE Industrial Electronics Society (pp. 7670-7674). IEEE.

[23] Vieira, J.P.A., Nunes, M.V.A., Bezerra, U.H. and Do Nascimento, A.C., 2009. Designing optimal controllers for doubly fed induction generators using a genetic algorithm. IET Generation, Transmission $\&$ Distribution, 3(5), pp.472-484. 
[24] Sekhar, V. and Ravi, K., 2019. Low-voltage ridethrough capability enhancement of wind energy conversion system using an ant-lion recurrent neural network controller. Measurement and Control,52(7-8), pp.1048-1062.

[25] Manohar, G., Venkateshwarlu, S. and Laxmi, A.J., 2020. A DFIG- based wind energy conversion system (WECS) for LVRT enhancement using a hybrid approach: an efficient MEHRFA technique. Soft Computing, pp.1-16.

[26] Mokryani, G. Siano, P. Piccolo, A and Calderaro, V., 2012. A fuzzy logic controller to increase fault ride-through capability of variable speed wind turbines. Applied Computational Intelligence and Soft Computing, 2012. 